\title{
Increased risk of flooding on the coast of Alicante (Region of Valencia, Spain)
}

\author{
J. Olcina Cantos, M. Hernández Hernández, A. M. Rico Amorós, and E. Martínez Ibarra \\ Inter-University Institute of Geography, University of Alicante, Alicante, Spain \\ Received: 15 June 2010 - Revised: 12 August 2010 - Accepted: 29 September 2010 - Published: 3 November 2010
}

\begin{abstract}
In the past two decades, episodes of flooding on the coast of Alicante (Spain) have led to substantial losses in human life in economic terms. With increased exposure to these phenomena comes also increased vulnerability. Given the various effects of flooding in areas of similar exposure, differences in vulnerability across regions at risk need to be analysed also in terms of the socioeconomic factors of the groups of society that may be affected, and of their perception of risk. This paper studies the increased risk of flooding in three locations on the Alicante coast as a result of urban occupation of areas subject to this hazard. The consequences of the most recent episodes in this area are analysed and a risk assessment, using survey-based research in the affected areas, is performed.
\end{abstract}

\section{Study area and subject relevance}

The province of Alicante is one of the main residential and tourist areas of the Spanish Mediterranean coast. At a European level, it is also one of the provinces with the highest risk of flooding (Schmidt, 2006), despite existing legal standards (water, spatial planning, environmental impact) that regulate land use according to the level of risk. Spatial planning for flood risk areas is a complicated issue in Spain (Fleischhauer et al., 2006) and, many times, it is not taken into account despite the existence of a legal framework ordering the contrary.

In the past three decades, episodes of flooding on the Alicante coast have led to substantial material losses and human victims. The reasons behind these trends lie in the increas-

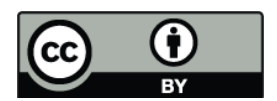

Correspondence to: M. Hernández (maria.hernandez@ua.es) ing human exposure and vulnerability to torrential rainfall and, above all, to the modification of hydrological parameters brought about by human occupation and alteration of natural areas and processes leading to increased runoff and flooding ratios.

\section{Objectives and methods}

This paper analyses vulnerability and exposure to the risk of flooding, and the management options developed to reduce this vulnerability in three towns on the Alicante coast between 1994 and 2005. Our working hypothesis, therefore, departs from an analysis of new "flood risk areas", with two objectives: (1) to assess and compare changes in vulnerability in these areas during the study period, using a series of selected indicators; and (2) to analyse the measures taken to reduce the risk of flooding, and their relation to the social perception of the existing risk.

Our integrated approach combined quantitative methodologies (which are of particular relevance in analysing flood risk and the different dimensions of vulnerability) and qualitative methodologies (perception surveys). The quantitative approach focused on three basic aspects: (1) statistical analysis of heavy rainfall episodes; (2) analysis of vulnerability due to physical exposure (mapping and analysing the occupation of flood areas by using SIG, and calculating changes in maximum flow rates and their concentration times depending on different land uses); and (3) vulnerability analysis in terms of resistance (statistical characterisation of economic, demographic and urban growth data). The qualitative risk analysis was based on surveys designed to address the institutional and social perceptions of the various dimensions of vulnerability, and used focus groups to assess the project's results. 

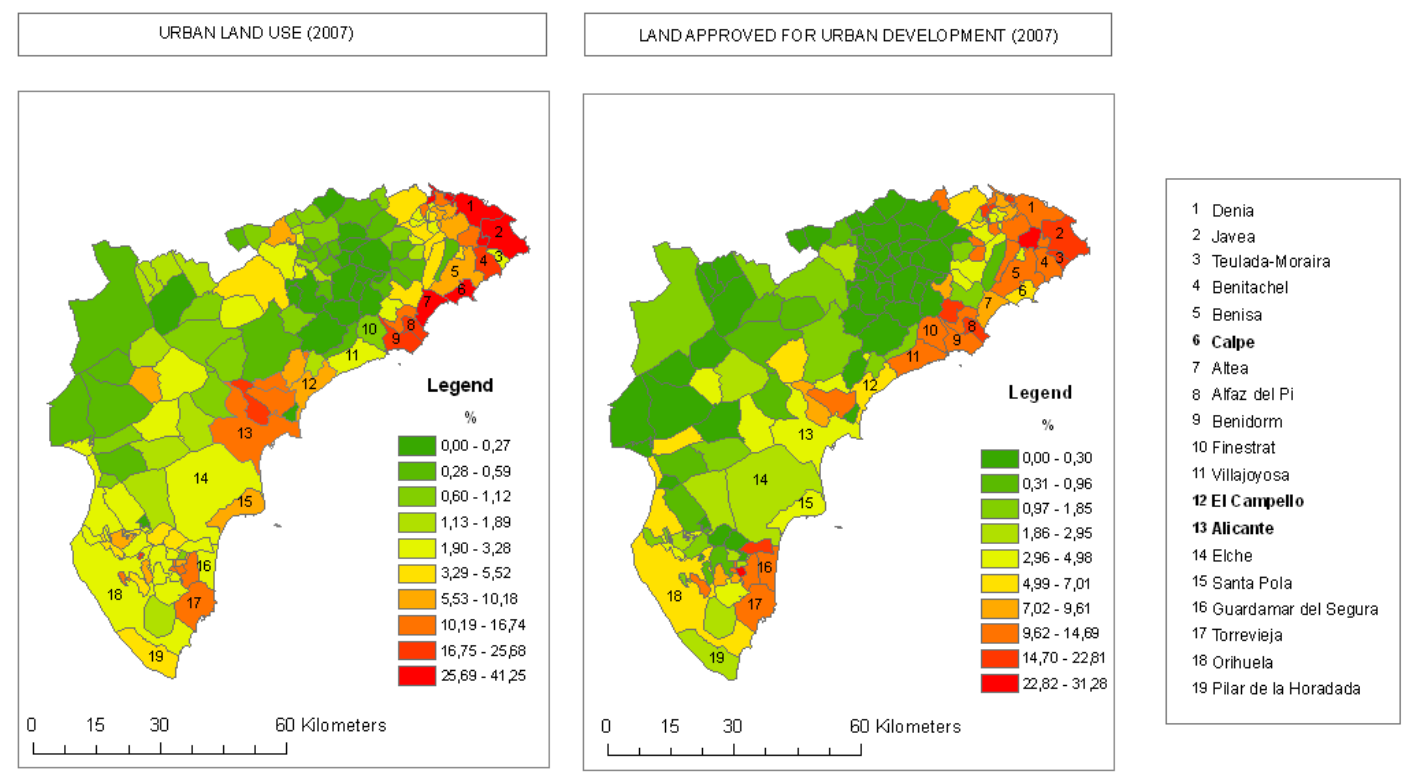

Fig. 1. Urban land use (developed) and land approved for urban development in the province of Alicante (2007).

The research involved the following stages:

1. Describing the socioeconomic and spatial effects of flood events in three municipalities of the Alicante coast between 1994 and 2005, by mapping "torrential rainfall focus points" and paying particular attention to summer storms, which, in recent years, have led to flood events. Until fairly recently, summer was not prone to heavy rainfall in this area.

2. Determining changes in physical exposure to the risk of flooding in the areas mentioned between 1994 and 2005, and defining and mapping new risk areas. More specifically, we are interested in showing how river beds have become incorporated into the urban fabric, and how internal drainage systems have been occupied due to the spread of tourism and residential-based growth. Social agents and affected parties were interviewed to define and assess vulnerability indicators in this particular aspect of physical exposure. In this way, social and economic vulnerability to torrential rains is increased. And, also, the occupation of river beds by urban uses involves a vulnerability increase of a fragile environmental system as well. Mediterranean ephemeral streams, therefore, lose their environmental values.

3. How "resistance" to risk on the Alicante coast, that is, the capacity of economic recovery of an area after a catastrophic event, has changed between 1994 and 2005. This involved analysing and assessing economic growth and material well-being in the study area.
4. How "resilience" to risk on the Alicante coast, or the public policies developed in order to recover the situation before the catastrophe, has changed between 1994 and 2005. This involved analysing both structural (e.g. hydraulic works) and non-structural (legal regulations regarding land use in flood areas) risk management measures. Particular attention was paid to assessing the degree to which these management measures were observed during the study period, particularly with regard to planning documents and the consideration that these documents give to flood risk.

5. How vulnerability has evolved in the study area since the period considered was assessed using indicators for the three dimensions of vulnerability, as explained previously.

\section{New risk areas created and flooding on the Alicante coast - significant examples}

Despite the considerable diversity of the area, the physical and ecological environment along the Alicante coastline presents a series of natural conditions that favour occasionally large river flows and flooding, which result from the complex combination of climatic, geomorphologic and hydrogeographic factors. The area rests on relatively young and active rock formations that generate a permanent dialectic between mountains and valleys, inland basins and coastal plains withal articulated by a dense network of rivers, streams and ravines. Flows in these fluvial streams increase considerably during situations of heavy rainfall caused by 
masses of cold polar and arctic air in the mid to upper troposphere, together with surface winds from the first or second quadrant and the formation of mesoscale convection structures. The Alicante coast has recorded levels of torrential rainfall in a 24-h period that remain among the highest in Europe, such as the $871 \mathrm{~mm}$ that fell in Jávea on 2 October 1957. In hydrogeographic terms, many fluvial collectors behave as true storm basins, with palm-shaped stream channels that help to synchronise and intensify the overflows reaching flood plains and coastal plains.

Natural factors are a determining factor in the frequency and perils posed by flood events, but on the Alicante coast spatial development processes also play a decisive role, particularly in terms of the growth of residential, commercial and leisure facilities, and of new communication infrastructures. Therefore, the past 20 years has seen the development of a new "risk space" in terms of both existing environmental conditions and the intensity of human occupation. The degree of risk to various natural hazards has been considerably intensified as vulnerability and human exposure to these hazards has increased, as with droughts and flooding, earthquakes or wind storms. An alert of this kind was given by the European Spatial Planning Observation Network (ESPON) in 2006 when it indicated that the province of Alicante was one the European areas most at risk from the dangers of flooding (ref).

There are two factors that explain the increase in exposure to this risk: the growth in population due to work-based and leisure, immigration and the spectacular growth of new urban spaces due to the spread of residential areas. Between 1998 and 2009 the population of Alicante increased from 1388933 to 1917012 persons. This growth is even higher in coastal towns, many of which doubled in size during the same period. For the whole of Alicante in $2009,45.6 \%$ of the population had been born outside the province, and 446368 residents were from foreign countries. To a large extent, this growth in population is connected to property development, a sector in which Alicante has displayed strong dynamics, as shown by data for 2006, year in which the province was fifth in Spain in the number of housing units built, behind Madrid, Barcelona, Murcia and Valencia, all of which with considerably higher population. This process has implied a notable increase in the urbanised area or has the potential for urbanisation in the coastal towns (Fig. 1). The presence of numerous torrential riverbeds that are normally dry means that these riverbeds or the spaces nearby are often used as construction sites, despite the existence of laws prohibiting such developments.

Therefore, new areas at risk of flooding on the coast of Alicante have been created by the spread of the urban expansion in both consolidated towns and recently created residential areas. There are various causes behind the factors that exacerbate the danger of flooding, but the following two can be especially highlighted in general terms: (a) full occupation, and bottlenecking or burying of natural waterways; (b) urban growth, with street layouts on ravines or former coastal wetlands, with deficient designs and no rainfall evacuation systems, leading to flooding or pooling of water from heavy rainfall.

There are several examples of these processes in the study area. In the Campo de Alicante, the area occupied by a former lagoon and by the Huerta de Alicante experienced an intensive transformation in the second half of the 20th century, which led to the growth of residential areas, commercial and sanitary installations and communication infrastructures. All these developments have completely altered flooding behaviour, by increasing the ratio of runoff water. Thus, the main feature of the fluvial elements in this district (which can be applied to the rest of the Alicante coast) is the strong waterproofing of the basin slopes due to the growing effect of urbanisation in the areas closest to the coast. Within this district, the town of El Campello has experienced intensive transformation due to land occupation for urban and tourist uses. Numerous short, steep ravines run from south to north in the area of the town's coves and along a $16 \mathrm{~km}$ stretch of the coastline (Amerador, Mesell, Aigues Baixes, Solana, Castañeta and Carritxar). All this area is full of residential developments which, in many cases, are built on top of fluvial channels and, therefore, unaware of the dangers incurred in episodes of torrential rainfall. This is the case of the Amerador, Coveta Fumá and Venta Lanuza developments, among others.

On the Southern Alicante coastline, the town of Orihuela abounds in ravines and former streams used to feed dryland crops, which have suffered major alterations due to the introduction of irrigation and urban development. One example of this is the Cañada de las Estacas (Fig. 2), where housing blocks have been built in the river channel itself, even at the upper end, where buildings can be observed on the actual banks of the river., These banks, moreover, are themselves sometimes used as a source of aggregate for the constructions. The same occurs in the section between the Cartagena highway and the N-332 road (Las Filipinas, Tierras Nuevas, Les Dolses and La Mosca), where there has been major urban and tourist-based expansion.

\section{Social perception of the risk of flooding - individual resilience and local risk management}

When assessing how the risk of flooding is perceived by society, it is particularly relevant to ascertain the opinion and participation of those affected by the risk areas established in the Water Framework Directive 2000/60/EC, the European Land Strategy (1999) and Directive 60/2007 on flood risk management. Following these recommendations, 285 surveys were conducted and processed, with a level of significance of at least $\pm 10 \%$, in the coastal towns of Calpe, Alicante and El Campello. We used a direct survey administered to 95 people in their homes in each town. These towns 

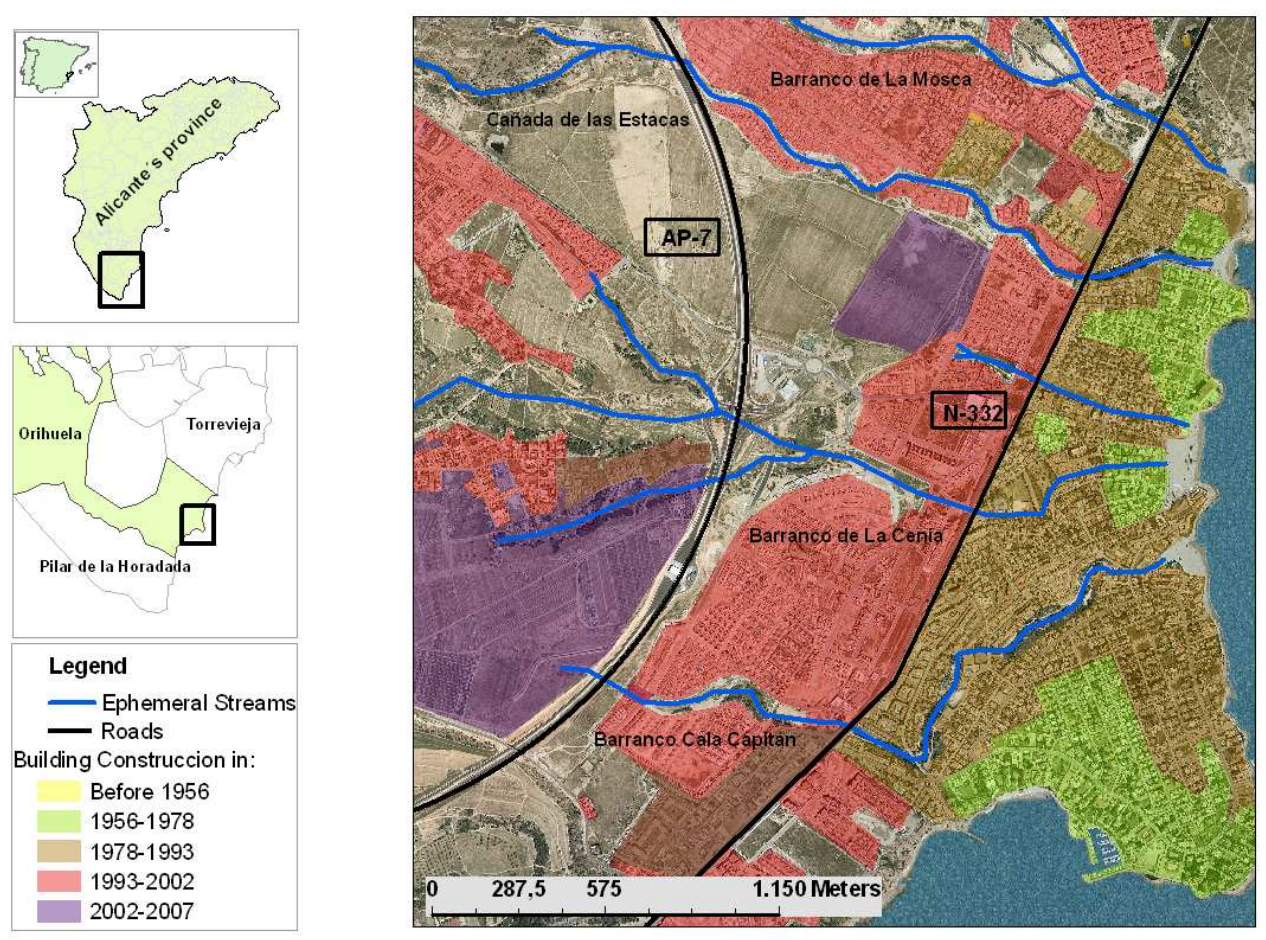

Fig. 2. Urban sprawl on the south coast of Orihuela.

were chosen for two basic reasons: (a) a high concentration of population and economic activity along the coastline; (b) existing contrasts between these local areas in terms of both their socioterritorial model and the actions taken to reduce vulnerability to the risk of flooding.

Two other reasons for choosing these towns are worth mentioning:

1. Calpe is an example of a town recently affected by heavy flooding (2007) and which lacks significant flood control works. Field work was carried out and 604 photographs were analysed in order to lay out the area and determine the height of the water that flooded the town.

2. El Campello is experiencing accelerated urban sprawl, under a situation of lack of planning or lack of compliance with planning, but has suffered no extraordinary catastrophes in recent years. Ravines and streams in the north and centre of the town were analysed.

3. The city of Alicante was chosen because of major investments in flood control works following the catastrophic flooding episode of 1997. The survey areas chosen focused on the most affected sectors as a result of historic flooding in 1982 and 1997, particularly streets on former ravines that have been incorporated into the urban grid and which were included in the AntiFlooding Plan.
The surveys were aimed at gathering information based on the social perception and assessment of aspects of resistance and resilience to flooding. A total of 23 questions were asked, divided into three main themes: (a) profile of participant; (b) experience of the risk of flooding; and (c) adaptation to this risk. The opinion poll was aimed exclusively at residents living in flood prone areas. With the aim of increasing the capacity of analysis and of improving the conclusions obtained, the results were cross-referenced by dividing the sample into permanent inhabitants and seasonal residents, as well as whether each group had been affected or not by any flooding events. More specifically, the results were analysed using two main variables: individual resilience and local management. For the latter, attention was paid to how inhabitants perceived local management practices and the proposals made to improve local flood planning and management.

Analysis of individual resilience focused on the measures taken by those affected, how they perceived the risk and the protective measures taken to deal with the risk of flooding. A majority of the citizens affected by flooding had taken no actions to cope with this risk, except in El Campello. Specifically, $93 \%$ of the interviewed in Calpe, $82 \%$ in Alicante and $46 \%$ in El Campello had not taken any individual measures. This is mainly due to the dominant urban environment in which the surveys were conducted: the results reflect that 98\% and 99\% of those surveyed in Calpe and Alicante lived in densely populated urban areas, whereas this relative figure 
dropped to $25 \%$ for El Campello, which would explain why the citizens of this town had taken measures of some kind to deal with flooding.

The majority of those surveyed believed that where they lived was not subject to flooding (Fig. 3), particularly in Alicante, where $90 \%$ of the participants gave this response, whereas the same opinion was given by $72 \%$ of the respondents in Calpe and El Campello. This would reflect the favourable assessment given about how the Anti-Flooding Plan has been implemented in Alicante, whereas almost no defensive works had been implemented in the other two towns. In general, as expected, those with the greatest sense of security were unaffected residents, particularly those who only live temporarily in the town (with the exception of Calpe). The main measures taken by participants to deal with the risk of flooding were home insurance and elements to protect their homes (waterproofing, measures to prevent water entering the house, etc.), and placing valuable objects away from danger areas. In El Campello, most of the permanent residents that have been affected $(86 \%)$ have taken some measure of protection of their own.

With regard to how the risk from flooding is perceived in the affected towns, the majority of those surveyed think that the risk is real and dangerous, conveying a pessimistic image of flooding (64\% in Calpe and 85\% in El Campello, with the lowest relative figure of $62 \%$ in Alicante). The lower figures for Calpe and Alicante are due to the fact that in both cases the authorities have carried out defensive works against flooding, mainly in the form of high-capacity rainwater collectors. El Campello, however, has some significant shortcomings in this regard, and the town has only carried out occasional work on the Cabrafich ravine and in the River Seco, although the technical services of the Group of Municipalities of L'Alacanti produced a "Study Report on Rainwater in El Campello" in 2007, which includes a detailed analysis of the risk of flooding and the possible defences that could be installed in each of the town's three risk areas (Calas, the town centre and Playa de Muchavista). In the case of El Campello, clear differences have been observed in the risk of flooding perceived by those that have been affected and by those that have not, as the former are of the opinion that the way the issue is managed is becoming worse (96\% compared with $74 \%$ ). However, it should be noted that a fairly large number of those surveyed (10\%) did not give an opinion on this matter.

Finally, the opinion of those surveyed should be considered concerning the measures that should be taken by local councils to reduce the risk of flooding. The most striking aspect in this regard is the high percentage of those surveyed that did not give an opinion or did not answer the question which may be related to the perception that flood management should be left to the "government" and is not a private affair. This answer was the first option chosen in Calpe and Alicante, and the third in El Campello, with figures of 38\%, $35 \%$ and $15 \%$, respectively. This state of opinion may also be explained by the lack of information that citizens have in terms of natural and environmental risks. The second most popular option is that building developments should be banned in flood prone areas, with figures of $12 \%$ in Calpe, 25\% in El Campello and 13\% in Alicante. In this regard, it should be noted that El Campello is where the highest figure was recorded, with $30 \%$ of the answers. In fact, this measure in particular was defended by participants that had been affected by flooding.

\section{Conclusions}

Despite the existence of legislation and plans that regulate land use on the coast of Alicante, large areas at risk of being flooded have been transformed and occupied (Greiving et al., 2006). This is because in Spain, before the effects of the catastrophic flooding that occurred in Biescas (August 1996), Alicante (September 1997) and Badajoz (November 1997), the risk of flooding was not contemplated in urban and spatial planning regulations. It was only as a result of article 15 of Spain's 2008 Land Law that the mapping of natural risks became a mandatory consideration on how subsequent land use is determined. In the Region of Valencia, the existence of a flood risk prevention plan as part of spatial planning initiatives (Patricova, 2003) has also been unable to halt processes of urban development on flood prone land. The result has been a major increase in the risk of flooding in most of the region's coastal towns. In the province of Alicante, the increase in built-up surface area in the towns of Denia, Calpe, Benidorm, El Campello, Alicante, Guardamar and Orihuela has not taken into consideration the local geography. Flood prone areas (riverbeds, shores and precarious drainage areas) have been developed as a result. Finally, we must pay attention to a process in which the occupation of flooding areas always goes ahead of planning to reduce the flood hazard. That land use planning cannot contain urban growth in flood prone land may be due either to the large amount of urban development approved before 2003 (year of implantation of the Patricova) or to the lack of control by the autonomous administration over the municipalities in what concerns the application of the rules established in the Patricova.

The analysis of the surveys presented in this paper reveals a lack of awareness among the population of the land on which they live, particularly in terms of the risk of flooding. Recent flooding events, however, have created a number of affected individuals, and awareness of the issue may be rising. However, the lack of knowledge is more noticeable among seasonal inhabitants or residents who have not lived in the area for very long. This last factor is of considerable significance given the notable increase in the coastal towns' population of retired and early-retired residents from Western and Northern Europe. It is interesting to emphasize the fact that the majority of people who live in areas of risk think that measures of risk management are the responsibility 


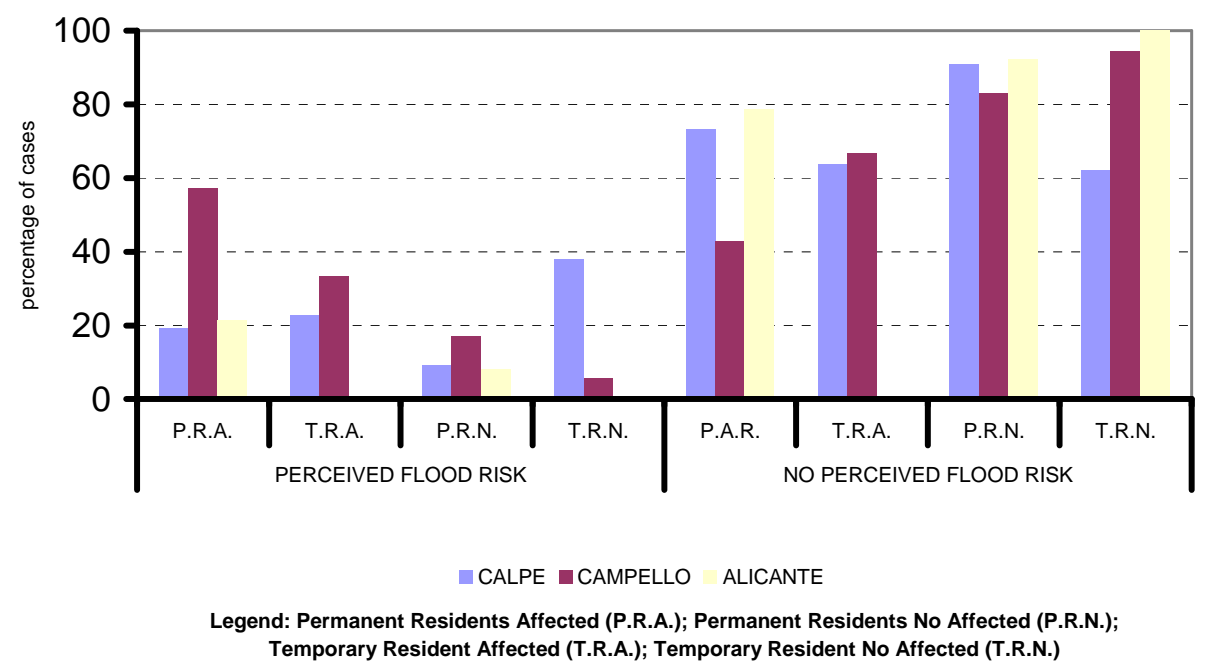

Fig. 3. Perception of flood risk by the inhabitants of three Alicante towns.

of the public administrations. But, in fact, experience shows that personal management of risk is an important argument in the set of practices to reduce the impacts of flooding.

The risk of flooding along the Alicante coast experienced in recent decades is combined with the uncertainty of future climate scenarios considered by climate modelling (IPCC, 2007). The Mediterranean region may be affected by an increase of its atmospheric features; in other words, atmospheric hazards (torrential rainfall, droughts, storms, etc.) may occur with greater frequency than they occur now. And this can only mean increased danger in the processes of natural risk. Thus, reducing exposure and vulnerability to atmospheric extremes is a necessary response to this uncertain climatic scenario.

Acknowledgements. This article is part of the research project "Models of land development and types of consumption of drinking water in residential tourist areas on the Alicante coastline" (CSO2009-12772-C03-03), funded by the Ministry of Science and Technology.

Edited by: M.-C. Llasat

Reviewed by: P. Schmidt-Thomé and two other anonymous referees

\section{References}

European Environment Agency: EEA Signals 2004, Copenhague, 2004.

European Environment Agency: Urban sprawl in Europe, EEA Report no $10 / 2006$.

Excimap: Handbook on good practices for flood mapping in Europe, European Commision, http://ec.europa.eu/environment/ water/flood_risk/flood_atlas/pdf/handbook_goodpractice.pdf), 2007.
Fleischhauer, M., Greiving, S., and Wanczura, S.: Natural Hazards and Spatial Planning in Europe, Versandbuchhandlung \& Verlag Dorothea Rohn, Dortmund, 204 pp., 2006.

Greiving, S., Fleischhauer, M., and Lückenkötter, J.: A Methodology for an Integrated Risk Assessment of Spatially Relevant Hazards, J. Environ. Plann. Man., 49(1), 1-19, 2006.

IGME y Consorcio de compensación de seguros: Pérdidas por terremotos e inundaciones en España durante el período 1987-2001 y su estimación para los próximos 30 años (2004-2033). Consorcio de Compensación de Seguros, Madrid, 2004.

IPCC: Climate Change 2007. Impacts, adaptation and vulnerability. (Working Group II Report), United Nations Environment Programme, http://www.ipcc.ch/publications_and_data/ar4/wg2/ en/contents.html, 2007.

Olcina Cantos, J.: Reducción del riesgo de inundaciones en el litoral mediterráneo español. El papel de la ordenación del territorio, in: Riesgo de inundaciones en el Mediterráneo occidental. Casa de Velázquez y Universidad de Alicante, 157-214, 2006.

Olcina Cantos, J., Martínez Ibarra, E., Zaragozí Zaragozí, e., Moltó Mantero, E. and Azorín Molina, C.: Creación de nuevos territorios de riesgo de inundación en la provincia de Alicante. El papel de la ordenación del territorio. Estudio de casos, in: Riesgos climáticos y cambio global en el Mediterráneo español, Fundación Centro de Estudios Ambientales del Mediterráneo, 189214, 2008.

ONU: Living with Risk: A Global Review of Disaster Reduction Initiatives, Nairobi, ISDR, 2004.

Schmidt-Thomé, P.: Natural and technological hazards and risks affecting the spatial development of European regions, Geol. S. Finl., Special Paper 42, Espoo, 2006. 